\title{
Cheating on Your Spouse: A Game-Theoretic Analysis
}

\author{
Amitrajeet A. Batabyal ${ }^{1 *}$, Hamid Beladi \\ ${ }^{1}$ Department of Economics, Rochester Institute of Technology, Rochester, USA \\ ${ }^{2}$ Department of Economics, University of Texas at San Antonio, San Antonio, USA \\ Email: ^aabgsh@rit.edu, Hamid.Beladi@utsa.edu
}

How to cite this paper: Batabyal, A.A. and Beladi, H. (2017) Cheating on Your Spouse: A Game-Theoretic Analysis. Theoretical Economics Letters, 7, 79-85. http://dx.doi.org/10.4236/tel.2017.71008

Received: December 15, 2016

Accepted: January 21, 2017

Published: January 24, 2017

Copyright (C) 2017 by authors and Scientific Research Publishing Inc. This work is licensed under the Creative Commons Attribution International License (CC BY 4.0).

http://creativecommons.org/licenses/by/4.0/

\begin{abstract}
In this note we analyze a game of marital infidelity. The husband can either be faithful to or cheat on his wife. The wife can either monitor or not monitor her husband. We first determine the best response correspondences of the two players. Second, we explain why there is no pure-strategy Nash equilibrium in the game under study. Third, we show that there exists a unique mixed-strategy Nash equilibrium in the game. Finally, we demonstrate the nexus between our marital infidelity game and the prominent Matching Pennies game.
\end{abstract}

\section{Keywords}

Cheating, Faithfulness, Monitoring, Mixed-Strategy, Static Game

\section{Introduction}

\subsection{Preliminaries}

The now deceased American actor and comedian Rodney Dangerfield once said "I told my wife the truth. I told her I was seeing a psychiatrist. Then she told me the truth: that she was seeing a psychiatrist, two plumbers, and a bartender." The humor notwithstanding, the available evidence discussed by Parker-Pope [1] and Lammers et al. [2] suggests that with the passage of time, this "love for variety" on the part of either spouse in a marriage has become more commonplace in the United States and hence so has the attendant phenomenon of marital infidelity.

At least since the appearance of the monopolistic competition model in Dixit and Stiglitz [3], economists have studied a love for variety and the impact that this love has on consumer welfare in considerable detail. Fair [4] has claimed that a love for variety can also be a rationale for the existence of extramarital affairs and it is this "marital infidelity" aspect of the love for variety that we study in this note. The reader should understand that the extent of marital infidelity is by no means small. In addition to the 
studies discussed by Parker-Pope [1] and Lammers et al. [2], research reviewed by Buss and Shackelford [5] shows that between 30 percent and 60 percent of all married individuals in the United States will engage in infidelity at some point in their marriages. Despite the seeming frequency of marital infidelity, there are very few studies of this phenomenon in the economics literature. We now briefly review the extant literature on this topic.

\subsection{Literature Review}

In a thoughtful paper, Fair [4] first builds a theoretical model to explain the allocation of an individual's time among spouse, paramour, and work. He then uses data from two magazine surveys to test the predictions of his model regarding the determinants of the time spent with a paramour and finds support for his theoretical model. More recently, Elmslie and Tebaldi [6] have used United States data from the General Social Survey (GSS) to study the extent to which demographic and educational variables impact the gender dimension of marital infidelity. They find that, in general, men and women react differently to the benefits and costs of having an affair.

When monitoring infidelity is difficult, the work of Sohn [7] shows that some people may prefer to stay single rather than be in a partnership because remaining single can be used as a disciplining device to forestall infidelity. Potter [8] uses data from the National Youth Survey to extend and reevaluate some of the empirical findings in Fair [4]. Specifically and unlike a finding obtained by Fair [4], Potter demonstrates that there is a negative relationship between years of marriage and the phenomenon of marital infidelity. A similar re-examination of the work of Fair [4] has also been conducted by Smith [9]. Using data sets from Germany, the United Kingdom, and the United States, Smith checks the robustness of the partial correlations between the phenomenon of infidelity and economic incentives.

Adamopoulou [10] shows empirically that in the United States, socioeconomic status is not a determinant of marital infidelity and that men and women are equally likely to be unfaithful. Kuroki [11] points out that the probability of being sexually unfaithful to a partner increases with the fraction of coworkers who are of the opposite sex for men but not for women. Elmslie and Tebaldi [12] use GSS data and show that although the drivers of happiness in a marriage differ between men and women, infidelity itself has similar effects on both the sexes. Finally, in a study that is closely related to our paper, Batabyal [13] uses a static game model to determine the optimal effort a wife ought to expend to monitor her potentially cheating husband.

Our understanding of marital infidelity has definitely been enhanced by the studies discussed in the foregoing three paragraphs. Even so, two points are now worth emphasizing and these two points together explain why the research conducted in this note is significant. First, the existing studies are mainly empirical and not theoretical in nature. Second, even though the marital infidelity phenomenon clearly has strategic aspects to it, with the exception of Batabyal [13], there are no game-theoretic analyses of marital infidelity ${ }^{1}$. Our analysis differs from Batabyal's [13] analysis in three ways. First, we study a different game. Second, we model the monitoring function differently.

${ }^{1}$ See Greenberg et al. [14] for an alternate theoretical perspective. 
Finally, we demonstrate the connection between our marital infidelity game and the prominent game known as Matching Pennies.

Given the above described lacuna in the literature, in our note, we focus on a married couple and analyze a game of marital infidelity. The husband can either be faithful to or cheat on his wife. The wife can either monitor or not monitor her husband. Section 2.1 describes the static game model ${ }^{2}$ we utilize to conduct the analysis. Section 2.2 determines the best response correspondences of the two players. Section 2.3 explains why there is no pure-strategy Nash equilibrium in the game under study. Section 2.4 solves for the unique mixed-strategy Nash equilibrium in the game between the husband and the wife. Section 2.5 demonstrates the nexus between our marital infidelity game and the Matching Pennies game. Section 3 concludes and then offers two suggestions for extending the research described in this note.

\section{Analysis}

\subsection{The Game Model}

Consider a man and a woman who are married and live together in the same house. This couple does not have any children and hence they are the object of each other's love and attention. In what follows, we assume that the wife is faithful to her husband but that the husband may cheat on his wife ${ }^{3}$. The husband (player 1) must choose whether to be faithful to his wife or to cheat on her. Therefore, the two pure strategies for the husband are denoted by $F$ for faithful and $C$ for cheat. The wife (player 2) must decide whether or not to monitor her husband's activities. As such, her two pure strategies are denoted by $M$ for monitor and $D$ for do not monitor.

We now need to specify the payoffs to the husband and to the wife from the pursuit of their two possible pure strategies. The reader should note that these payoffs will need to capture the oppositional nature of the game-theoretic interaction between the husband and the wife in the context of marital infidelity. Keeping this point in mind, we suppose that the game of interest can be described in matrix form in Table 1.

Table 1. The marital infidelity game in matrix form.

\begin{tabular}{|c|c|c|c|}
\hline \multirow{4}{*}{$\begin{array}{l}\text { Husband } \\
\text { (Player 1) }\end{array}$} & & Wife (Player 2) & \\
\hline & & Monitor $(M)$ & Don't Monitor $(D)$ \\
\hline & Faithful $(F)$ & 1,1 & 1,2 \\
\hline & Cheat $(C)$ & 0,2 & 2,1 \\
\hline
\end{tabular}

With this background in place, our next task is to determine the best response correspondences of the two players.

\subsection{Best Response Correspondences}

Let $u_{1}(\cdot, \cdot)$ and $u_{2}(\cdot, \cdot)$ denote the payoff functions of the husband (player 1 ) and the ${ }^{2}$ See Tadelis ([15], pp. 43-128) for a textbook exposition of such static games.

${ }^{3}$ There would be no substantive change in our analysis if the husband is assumed to be faithful and the wife the possible cheater. Therefore, this assumption is without loss of generality. 
wife (player 2). In addition, let $p \geq 0$ denote the probability that the husband chooses $F$ and hence $(1-p) \geq 0$ denotes the probability that he chooses $C$. Similarly, let $q \geq 0$ denote the probability that the wife selects $M$ and so $(1-q) \geq 0$ denotes the probability that she selects $D$.

Some thought tells us that the husband will remain faithful to his wife (play $F$ ) and not cheat (play $C$ ) as long as his payoff from remaining faithful exceeds his payoff from cheating. Mathematically, straightforward algebra indicates that this happens when

$$
u_{1}(F, q)>u_{1}(C, q) \Leftrightarrow 1>2(1-q) \Leftrightarrow q>1 / 2 .
$$

Using the logic leading to (1), it is clear that the husband will prefer to cheat and not remain faithful if and only if $q<1 / 2$. Finally, when $q=1 / 2$ the husband will be indifferent between remaining faithful to and cheating on his wife.

Moving on to the incentives confronting the wife, we see that she will prefer to monitor her husband's activities (play $M$ ) provided that her payoff from monitoring is greater than her payoff from not monitoring (playing $D$ ). Once again, elementary algebra tells us that monitoring will occur when

$$
u_{2}(M, p)>u_{2}(D, p) \Leftrightarrow p+2(1-p)>2 p+(1-p) \Leftrightarrow p<1 / 2 .
$$

From the result in (2) it follows that the wife will not monitor her husband's activities when $p>1 / 2$ and that she will be indifferent between monitoring and not monitoring when $p=1 / 2$.

Using the analysis in the preceding two paragraphs, we can express the best response correspondences of the husband and the wife. To this end, let $R_{1}^{*}(q)$ and $R_{2}^{*}(p)$ denote the husband's and the wife's best response correspondences. We get

$$
R_{1}^{*}(q)= \begin{cases}p=0 & \text { if } q<1 / 2 \\ p \in[0,1] & \text { if } q=1 / 2 \\ p=1 & \text { if } q>1 / 2\end{cases}
$$

and

$$
R_{2}^{*}(p)=\left\{\begin{array}{llc}
q=1 & \text { if } & p<1 / 2 \\
q \in[0,1] & \text { if } & p=1 / 2 \\
q=0 & \text { if } & p>1 / 2
\end{array}\right.
$$

Our next task in this note is to point out that a pure-strategy Nash equilibrium does not exist in the game between the husband and the wife that we have been studying thus far.

\subsection{Pure-Strategy Nash Equilibrium}

Inspecting Table 1, we see that when the husband plays the pure strategy $F(C)$ it is optimal for his wife to play the pure strategy $D(M)$. Looked at from the wife's perspective, when she plays the pure strategy $M(D)$ it is optimal for her husband to play the pure strategy $F(C)$. This state of affairs tells us that in the game under study, we have a situation where one player wants to match the action of the other player (if the husband is faithful then the wife prefers not to monitor him) but the other player wants to avoid this matching (if the wife does not monitor then the husband prefers to cheat 
on her). This explains why there is no pure-strategy Nash equilibrium in the game between the husband and the wife. This notwithstanding, we now show that there exists a unique mixed-strategy Nash equilibrium in this husband-wife game.

\subsection{Mixed-Strategy Nash Equilibrium}

To find the mixed-strategy Nash equilibrium, note from Equation (3) and our analysis thus far that the husband (player 1) will be willing to mix between his two pure strategies $F$ and $C$ if and only if $u_{1}(F, q)=u_{1}(C, q)$ and this last condition holds only when $q=1 / 2$. Similarly, Equation (4) and some thought together tell us that the wife (player 2) will be willing to mix between her two pure strategies $M$ and $D$ if and only if $u_{2}(M, p)=u_{2}(D, p)$. This last condition holds only when $p=1 / 2$. Putting this information about the probabilities $p$ and $q$ together, we conclude that there exists a unique mixed-strategy Nash equilibrium $(p, q)=(1 / 2,1 / 2)$ in the husbandwife game that we have been studying here. Specifically, in this game, the husband is faithful to his wife with probability $p=1 / 2$ and his wife chooses to monitor his activities also with probability $q=1 / 2^{4}$. Our last task in this note is to demonstrate the nexus between our marital infidelity game and the well-known Matching Pennies game.

\subsection{Connection with the Matching Pennies Game}

In the Matching Pennies game, players 1 and 2 each put a penny on a table simultaneously. If the outcome is two heads or two tails then player 1 gets to keep both pennies. Otherwise, player 2 keeps the two pennies. This game is well known and is routinely discussed in game theory textbooks such as Tadelis ([15], pp. 108-111).

The point to note is that the incentives facing the husband and the wife in our marital infidelity game and the incentives facing the two players in the Matching Pennies game are very closely related. Specifically and consistent with the discussion in section 2.3 , in both games, we have a situation in which one player wants to match the action of the other player but the other player wants to countermand this matching. This is also why in both these games, there is no pure-strategy Nash equilibrium and the only Nash equilibrium is in mixed strategies. This completes our game-theoretic analysis of marital infidelity.

\section{Conclusions}

In this note we provided one of the first game-theoretic studies of marital infidelity. Since our objective in this note has been to report the results of abstract theoretical research, the question of seeking "truth from facts" does not arise. Specifically, we analyzed a game model of cheating on one's spouse. The husband could either be faithful to or cheat on his wife. The wife could either monitor or not monitor her husband. We first ascertained the best response correspondences of the two players. Second, we explained why there was no pure-strategy Nash equilibrium in the game under study. Third, we showed that there existed a unique mixed-strategy Nash equilibrium in the

${ }^{4}$ Pictorially, we are looking for a pair of choices $(p, q)$ for which the two best response correspondences in equations (3) and (4) intersect. If we were to plot the two best response correspondences in $(p, q)$ space then it is easy to see that these two correspondences would intersect only at $p=q=1 / 2$. 
game. Finally, we pointed out the nexus between our marital infidelity game and the well-known Matching Pennies game.

The analysis in this note can be extended in a number of directions. Here are two suggestions for extending the research described here. First, it would be useful to introduce income heterogeneity between the husband and the wife into the model and to then study how this heterogeneity influences the likelihood of cheating either by the husband or by the wife. Second, it would also be interesting to introduce children into the model and then study marital infidelity when the husband and/or the wife care not only about their own welfare but also about the welfare of their children. Game-theoretic studies of marital infidelity that incorporate these features of the problem into the analysis will provide additional insights into a phenomenon that has salient economic and psychological ramifications for a non-trivial proportion of society.

\section{Acknowledgements}

We thank an anonymous reviewer for helpful comments on a previous version of this paper. In addition, Batabyal acknowledges financial support from the Gosnell endowment at RIT and he thanks Cassandra Shellman for her assistance in formatting the paper. The usual disclaimer applies.

\section{References}

[1] Parker-Pope, T. (2008) Love, Sex, and the Changing Landscape of Infidelity. New York Times, 27 October 2008.

[2] Lammers, J., Stokes, J.I., Jordan, J., Pollman, M. and Stapel, D.A. (2011) Power Increases Infidelity among Men and Women. Psychological Science, 20, 1-7.

[3] Dixit, A.K. and Stiglitz, J.E. (1977) Monopolistic Competition and Optimum Product Diversity. American Economic Review, 67, 297-308.

[4] Fair, R.C. (1978) A Theory of Extramarital Affairs. Journal of Political Economy, 86, 45-61. https://doi.org/10.1086/260646

[5] Buss, D.M. and Shackelford, T.K. (1997) Susceptibility to Infidelity in the First Year of Marriage. Journal of Research in Personality, 31, 193-221.

https://doi.org/10.1006/jrpe.1997.2175

[6] Elmslie, B. and Tebaldi, E. (2008) So What Did You Do Last Night? The Economics of Infidelity, Kyklos, 61, 391-410. https://doi.org/10.1111/j.1467-6435.2008.00408.x

[7] Sohn, K. (2008) Why Are There Singles: Being Single in Equilibrium as a Partner Disciplining Device. Economics Bulletin, 10, 1-6.

[8] Potter, J. (2011) Reexamining the Economics of Marital Infidelity. Economics Bulletin, 31, 41-52.

[9] Smith, I. (2012) Reinterpreting the Economics of Extramarital Affairs. Review of Economics of the Household, 10, 319-343. https://doi.org/10.1007/s11150-012-9146-9

[10] Adamopoulou, E. (2013) New Facts on Infidelity. Economics Letters, 121, 458-462. https://doi.org/10.1016/j.econlet.2013.09.025

[11] Kuroki, M. (2013) Opposite-Sex Coworkers and Marital Infidelity. Economics Letters, 118, 71-73. https://doi.org/10.1016/j.econlet.2012.09.023

[12] Elmslie, B. and Tebaldi, E. (2014) The Determinants of Marital Happiness. Applied Economics, 46, 3452-3462. https://doi.org/10.1080/00036846.2014.932047

[13] Batabyal, A.A. (2016) Marital Infidelity: A Game-Theoretic Analysis. Unpublished Manu- 
script, Rochester Institute of Technology.

[14] Greenberg, J., Luo, X., Oladi, R. and Shitovitz, B. (2002) (Sophisticated) Stable Sets in Exchange Economies. Games and Economic Behavior, 39, 54-70. https://doi.org/10.1006/game.2001.0890

[15] Tadelis, S. (2013) Game Theory. Princeton University Press, Princeton.

Submit or recommend next manuscript to SCIRP and we will provide best service for you:

Accepting pre-submission inquiries through Email, Facebook, LinkedIn, Twitter, etc. A wide selection of journals (inclusive of 9 subjects, more than 200 journals)

Providing 24-hour high-quality service

User-friendly online submission system

Fair and swift peer-review system

Efficient typesetting and proofreading procedure

Display of the result of downloads and visits, as well as the number of cited articles Maximum dissemination of your research work

Submit your manuscript at: http://papersubmission.scirp.org/

Or contact tel@scirp.org 